\title{
Incorporation of Humanistic Quality Education Into The Practice of Dermatology and Venereology Training Research
}

\section{Xian-Wen Qiu}

Southern Medical University

Xiang-Bin Mi

Southern Medical University

Shan-Shan Wei

Southern Medical University

Lu Yan ( $\sim$ michelley8051@126.com )

Southern Medical University

\section{Research Article}

Keywords: Dermatology, Clinical practice, Medical humanistic education

Posted Date: October 22nd, 2021

DOl: https://doi.org/10.21203/rs.3.rs-970930/v1

License: (c) (i) This work is licensed under a Creative Commons Attribution 4.0 International License. Read Full License 


\section{Abstract \\ Background}

The transformation of the medical pattern into the biological-sociological and psychological medical model has made the importance of humanities in medical education increasingly prominent. This study analyzes the effectiveness and importance of integrating humanistic qualities into clinical teaching in dermatology.

\section{Methods}

During July 2016 to August 2020, interns training in Departments of Dermatology, Zhujiang Hospital, 200, according to the order of student number of grouping experimental group and control group, four groups of 50, respectively, the control group of interns on conventional teaching in practice stage, while the experimental group of intern trainee phase combination of humanity quality education in teaching, compared two groups of interns teaching and learning effects.

\section{Results}

Medical history collection/interrogation techniques, practical operation and observation of history writing scores of the experimental group of interns were significantly higher than those of the control group, and the experimental group of interns humanistic quality education related indicators were significantly better than the control group $(P<0.05)$.

\section{Conclusions}

The results put forward some countermeasures and suggestions for cultivating and optimizing the humanistic care spirit of medical students.

\section{Background}

Increasing the humanistic quality of education provided to medical students is an important and challenging task in higher medical education. The Ministry of Education and the Ministry of Health jointly promulgated the "Chinese Undergraduate Medical Education Standards for Clinical Medicine Specialty" in 2016 [1]. This standard was drawn up based on the international medical education standards and adapted to China's national conditions. The developmental requirements and standards include humanities quality education regulations. Medical schools should integrate humanities, social sciences, and behavioral sciences into professional medical education. In China, we attach importance to the cultivation of the quality of careers. Medical schools and teachers must actively adjust the content and 
optimize the proportion and importance of the humanities and the social and behavioral sciences in the curriculum.

Departments of dermatology and venereology provide a wide range of services. Patients often need to expose rashes on private areas. Because patient privacy is involved, many patients are not very cooperative with collection of information on medical history or during clinical examination when students are present, especially when there are many students [2]. They often refuse to be part of the learning object. It is also difficult to find various standardized course content for the teaching process, and the signs and symptoms of lesions are not typical during follow-up. Many students feel that the content of learning in dermatology clinical teaching is restricted. The research involved humanistic quality education for students who have been receiving clinical training in hospitals for some time. The research has achieved satisfactory results through the comparison of students before and after instruction.

\section{Materials And Methods}

\subsection{General information}

The control group contained 50 students receiving clinical practice instruction in the dermatology department of the hospital, and their student ID numbers ended in an odd digit; they were randomly sampled from July 2016 to July 2018. We performed another random sampling from August 2018 to August 2020 to enroll 50 similar students whose student ID numbers ended in an even digit for the experimental group. These students received an instruction program incorporating a humanistic quality. We compared the two-stage teaching effect. The control group had 23 men and 27 women with an average age of $22.6 \pm 1.3$ years. The experimental group had 20 men and 30 women in the experimental group with an average age of $23.1 \pm 0.9$ years. There was no statistically significant difference in such baseline data as age or gender composition of the two groups of students.

\subsection{Methods}

In the control group, the interns received regular teaching during the teaching stage, that is, traditional teaching-style teaching. The experimental group of interns were given instruction with humanistic quality education as part of the teaching. First, we selected senior teachers with rich work experience to conduct professional training for medical teachers, so that they would have a highly comprehensive understanding of various diseases. Combined with the syllabus, special emphasis was placed on nursing content and skills specific to different diseases [3]. These younger teachers had to prepare the teaching model for related specialty examinations according to the clinical symptoms. They had to manage patient understanding of medical history inquiry, patient marital status, and patient medical history during the diagnosis and treatment processes. Teachers had to show how the order of consultation should be done in this process and how to communicate with patients as naturally as possible to avoid embarrassing scenes $[4,5]$. The instructors then allowed students to perform medical information inquiry, physical examinations and provided each one a corresponding score along with corresponding reasons 
and conclusions for each diagnosis. Finally, the learning effects on the two groups of interns were assessed, and humanistic literacy status was assessed using questionnaires [6,7].

The appraisal of the quality of interns involves assessing their ability to collect medical histories, perform physical examinations, and create medical records. The maximum scores for these three categories are 30,30 , and 40 points, respectively (see Figure 1). Two teachers scored independently, and the average was taken as the final score. The higher the score, the better the mastery of skills. The assessment of humanistic quality involves students' interest in learning, adaptability, concern for patients, and overall quality (see Figure 2). Self-evaluation of questionnaires and pairwise mutual evaluation allow three options: 'Yes', 'No' and 'No comment'. Mutual evaluations are considered affirmative only when 'Yes' in both self-evaluation and pairwise evaluation are considered.

\subsection{Statistical methods}

The SPSS 20.0 software package was used for data analysis. The Pearson $\chi 2$ test was used to count data, and the $t$ test was used for comparison of measurement data between groups. $P<0.05$ was considered statistically significant.

\section{Results}

The interns in the experimental group showed better performance than controls in collecting medical histories, physical examination, and writing medical records, and the difference was statistically significant $(P<0.05)$ (see Table 1$)$. Related evaluation indicators of humanistic quality education of the interns in the experiment group were significantly better than those in the control group, and the difference was statistically significant $(P<0.05)$ (see Table 2 ).

Table 1

Comparison of the evaluation results of the two groups of interns (points)

\begin{tabular}{|lllll|}
\hline Groups & $\begin{array}{l}\text { Number of } \\
\text { Cases }\end{array}$ & $\begin{array}{l}\text { Medical History } \\
\text { Collection and Skills }\end{array}$ & $\begin{array}{l}\text { Physical } \\
\text { Examination Practice }\end{array}$ & $\begin{array}{l}\text { Medical Record } \\
\text { Writing }\end{array}$ \\
\hline $\begin{array}{l}\text { Control } \\
\text { group }\end{array}$ & 50 & $19.64 \pm 1.93$ & $19.68 \pm 2.32$ & $26.91 \pm 2.41$ \\
\hline $\begin{array}{l}\text { Experimental } \\
\text { group }\end{array}$ & 50 & $21.78 \pm 3.04$ & $22.10 \pm 3.09$ & $30.40 \pm 4.49$ \\
\hline$T$ & 3.717 & 4.779 & 5.035 \\
\hline$P$ value & 0.001 & 0.000 & 0.000 \\
\hline
\end{tabular}


Table 2

Comparison of humanistic quality scores of interns in the two groups [n (\%)]

\begin{tabular}{|llllll|}
\hline Groups & $\begin{array}{l}\text { Number of } \\
\text { Cases }\end{array}$ & $\begin{array}{l}\text { Learning } \\
\text { Interests }\end{array}$ & $\begin{array}{l}\text { Response } \\
\text { Ability }\end{array}$ & $\begin{array}{l}\text { Stress } \\
\text { Management }\end{array}$ & $\begin{array}{l}\text { Empathy } \\
\text { Competency }\end{array}$ \\
\hline Control group & 50 & $25(50.0)$ & $26(52.0)$ & $33(66.0)$ & $30(60.0)$ \\
\hline $\begin{array}{l}\text { Experimental } \\
\text { group }\end{array}$ & 50 & $36(72.0)$ & $39(78.0)$ & $42(84.0)$ & $40(80.0)$ \\
\hline$X^{2}$ & & 5.086 & 7.429 & 4.32 & 4.762 \\
\hline$P$ value & & 0.024 & 0.006 & 0.038 & 0.029 \\
\hline
\end{tabular}

\section{Discussion}

With the reform of the medical system and the increase in patients' requirements for life and health, people's reliance on and acceptance of information regarding health and medicine in the Internet age have become increasingly greater, and the awareness of the need to protect patients' rights has gradually increased. As a medical worker, clinical teaching is an important transitional stage from students to physicians. Medical students also face more problems in the initial stage of clinical teaching $[6,7]$. Therefore, adding a more humanistic quality to clinical education in dermatology has considerable prospects for application and exploration value.

Patients' privacy is violated in varying degrees during the treatment process in the clinical diagnosis and treatment of dermatological diseases. It is common for patients to be unwilling to cooperate with students for consultation and examination. There have been many embarrassing situations. The collection of patient history and dermatological examinations are both tedious and important in clinical teaching. In clinical teaching, it is not only necessary to guide patients to reveal their medical history regarding dermatology-related diseases but also to strengthen students' communication skills and promote the formation of students' clinical thinking and operational skills. Moreover, it is necessary for teachers to assess students' learning outcomes.

In this study, the experimental group's medical history collection skills, consultation skills, physical examination skills, and medical history writing skill scores were significantly higher than that of the control group. The indicators related to the quality of humanities education were all significantly higher for the interns in the experimental group than for those in the control group.

The integration of humanistic quality education into early practical teaching can prevent certain problems to some extent, and it can significantly facilitate the acquisition of clinical skills. In clinical teaching, the humanistic spirit and teaching skills of dermatology teachers should be improved. In the collection of medical history, teachers and students should have a more comprehensive control over the content of consultation and the scope to dig into the relevant content of dermatology teaching. Therefore, the humanistic spirit is reflected in each part of this process, and the clinical-related skills of dermatology and 
patient communication are introduced and discussed in detail. In this process, teachers also need to provide examples for others with both precepts and deeds so that students receive a good humanistic education. It is necessary to adhere to the patient-centered approach and comprehensively understand medicine, ethics, sociology, and laws and regulations relevant to the patient's condition. In addition, humanistic ideas in textbooks should be promoted, and the senior students in the medical field should be guided to study them. The spirit of questioning and the quality of dedication, which we all saw when many medical workers either rushed to the front lines of the pandemic or remained at their posts during COVID-19 outbreaks [8]-this collective medical ethics atmosphere formed by individual connections is particularly important. In particular, the sacrifices doctors made during the COVID-19 pandemic have had a direct and strong influence on the values of young medical students, setting a good example for them.

In the clinical teaching of dermatology, it is necessary to closely integrate humanistic quality education to promote student communication and improve student communication skills. Clinical medicine, as a professional and communication discipline, requires not only a solid foundation of medical knowledge but also a humanistic spirit, strong training, and good communication skills to establish doctor-patient communication. New doctors can easily guide patients to a detailed and accurate understanding of their own condition if they can combine psychology and communication. In the clinical teaching of interns, students now have many opportunities to express their views and opinions, optimize the quality of communication, and obtain a comprehensive understanding of patients' needs; moreover, cultural education can be integrated into the program to improve students' communication and interpersonal skills. Finally, the effect of medical humanities education must be evaluated from multiple perspectives while emphasizing the need to pay attention to the diversification of evaluation subjects.

Combining humanistic quality education in the clinical teaching of dermatology can reduce the incidence of medical disputes. With the increase in people's healthcare needs and awareness, there have been an increasing number of doctor-patient disputes in the medical industry, and these have had a negative impact on social stability and a certain negative effect on the medical order and the international reputation of the medical community [9]. This is also related to the need to improve the education of the public. There are a large number of clinical experimental results that show that non-technical doctorpatient communication is very important to this process [10]. The practice of treating patients without taking their mental state into account still exists. As the epitaph of the medical master Trudeau states: "To Cure Sometimes, to Relieve Often, to Comfort Always," providing patients with humanistic care during diagnosis and treatment has become important in a teaching content. Through the improvement of any details in clinical diagnosis and treatment, patients can receive better attention and care than before. In the clinical process, doctors must uphold the patient-oriented service idea of considering and solving problems from the patients' perspective, thereby reducing the occurrence of medical disputes. The doctors must lay a good foundation for the creation of a harmonious society. In the guidance of humanistic quality education, they should not only help patients overcome the disease but also adjust their emotional state. Doctors must ensure that the patient feels understood, respected, and cared for during the diagnosis and treatment process, and they must strive to improve the humanized service. 


\section{Conclusion}

Combining humanistic quality education in early dermatology clinical education and teaching can significantly facilitate learning by interns. Through guided teaching, students can consolidate their practical skills in the diagnosis and treatment of dermatology patients. It is therefore necessary to pay attention during the early education of clinical interns from a humanistic perspective.

\section{Declarations}

\section{Ethics approval and consent to participate}

No applicable.

\section{Consent for publication}

No applicable.

\section{Availability of data and material}

All data generated or analysed during this study are included in this published article.

\section{Competing interests}

The authors declare no potential conflict of interest.

\section{Funding}

This study was supported in part by grants from National Natural Science Foundation of China (Grant number 82003370) and Natural Science Foundation of Guangdong Province (Grant number 2019A1515012225).

\section{Authors' contributions}

LU YAN conceived the study and led in, the design, data collection, analysis and interpretation of the research supported by XIAN-WEN QIU, XIANG-BIN MI and SHAN-SHAN WEI. LU YAN drafted the first version of the manuscript with XIAN-WEN QIU, XIANG-BIN MI and SHAN-SHAN WEI providing critical review and revision and correctness for English. All authors read and approved the final manuscript.

\section{Acknowledgements}

The authors gratefully acknowledge the supports from National Natural Science Foundation of China (Grant number 82003370) and Natural Science Foundation of Guangdong Province (Grant number 2019A1515012225). 


\section{Authors' contribution}

LU YAN conceived the study and led in, the design, data collection, analysis and interpretation of the research supported by XIAN-WEN QIU, XIANG-BIN MI and SHAN-SHAN WEI. LU YAN drafted the first version of the manuscript with XIAN-WEN QIU, XIANG-BIN MI and SHAN-SHAN WEI providing critical review and revision and correctness for English. All authors read and approved the final manuscript.

\section{Authors' information}

XIAN-WEN QIU is an associate professor and educational dermatologist in the Department of Dermatology, Zhujiang Hospital, Southern Medical University in Guangzhou.

Email: 372835208@qq.com

XIANG-BIN MI is an associate professor and educational dermatologist in the Department of Dermatology, Zhujiang Hospital, Southern Medical University in Guangzhou.

Email: xiangbinmi12@163.com

SHAN-SHAN WEl is an attending doctor with doctorate degree in the Department of Dermatology, Zhujiang Hospital, Southern Medical University in Guangzhou.

Email: shanshanwei@163.com

LU YAN is an associate professor and educational dermatologist in the Department of Dermatology, Zhujiang Hospital, Southern Medical University in Guangzhou.

Email: michelley8051@126.com; yanlu710@163.com

\section{References}

1. The Ministry of Education's Clinical Medicine Professional Certification Working Committee. China's Undergraduate Medical Education Standards (Clinical Medicine Specialty 2016 Edition) [M]. Peking University Medical Press. 2017.ISBN 9787565917011

2. Jory S. S, Stella Ng, Emilia K, Csilla K, Aimee H, Arno K, Tulin C, Darlene F, Najma A, Ori R. Humanistic education in surgery: a "patient as teacher" program for surgical clerkship. Can J Surg. 2020;63(3):E257-E260.

3. Fawaz MA, Hamdan-Mansour AM, Tassi A. Challenges facing nursing education in the advanced healthcare environment. Int J Afr Nurs Sci. 2018;9(February):105-110.

4. Ingrid S, Lisette W, Rebecca MK, Remy M J P R, Sofie M M L. Relationship quality in higher education and the interplay with student engagement and loyalty. Br J Educ Psychol. 2021; 24;e12455.

5. Abdul W K, Ahsan S, Gohar W, Raheela Y. Challenges towards quality assurance of Basic Medical Education in Pakistan. Pak J Med Sci. 2020;36(2):4-9. 
6. Joanne G, Ayelet K, Cynthia W, G Ross B, Beverly B, Maitreya C, Christine S, Lianne J, Kaveh S, Brian W. Interprofessional and multiprofessional approaches in quality improvement education. Adv Health Sci Educ Theory Pract. 2021;26(2):615-636.

7. Peipei S, Wei T. Emphasizing humanities in medical education: Promoting the integration of medical scientific spirit and medical humanistic spirit. Biosci Trends. 2017;11(2):128-133.

8. Luo H, Yao H, Xi Y, Zhang Z, Li J, Li J, Wang X, Zhong Z, Lv Y. Protective and Risk Factors for Medical and Nursing Staff Suffering From Psychological Symptoms During COVID-19. Front Psychol. 2021 Apr 16;12:603553.

9. Editorial. Protecting Chinese doctors. The Lancet. 2020;395(10218):90.

10. Wald HS, McFarland J, Markovina I. Medical humanities in medical education and practice[J]. Med Teach. 2019;41(5):492-496.

\section{Figures}

\section{Medical History Collection and Skills (30 scores)}

1) This student asked basic questions completely. (10 scores)

2) This student was able to make a distinction between the main and lateral issues in the subject matter, as well as capture essential features. (10 scores)

3) This student corrected patient's misconceptions about the subject matter with straightaway and understandable language. (10 scores)

\section{Physical Examination Practice (30 scores)}

1) The body physical examination was standardized and correct. (10 scores)

2) The body physical examination was comprehensive, orderly and focused. (10 scores)

3) Dignified appearance, generous manners, sincere and amiable attitude (10 scores)

\section{Medical Record Writing (40 scores)}

1) This student was able to make adequate summaries and accurate expression. (10 scores)

2) Medical records were written in a standardized manner with medical terms. (10 scores)

3) Clear writing, smooth sentences and correct punctuation; The mistakes in medical records were revised in accordance with the regulations. (10 scores)

4) Auxiliary examination could be accurately written and interpreted, which was helpful for differential diagnosis. (10 scores)

\section{Figure 1}

Questionnaire in basic medical practice for teachers 
Self-evaluation evaluation

1) I was interested in this medical practice process.

2) Our conversation and physical examination were smooth and harmonious.

3)I felt not very challenging and easy to control the situation.

4)I can feel patients' emotion change and recognize their need.
Yes No No comment

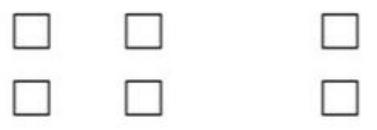

\section{Pairwise evaluation}

1)This student actively participated and demonstrated enthusiasm during the process.

2)This student had a positive attitude and response quickly.

3)This student showed good adaptability and could handle some emergencies.

4)This student showed sympathy and reliability.

\section{Figure 2}

Questionnaire in humanistic quality for students 